\title{
A SIMPLE AND CONVENIENT SYSTEM OF KEEPING GENERAL ENTOMOLOGICAL RECORDS
}

\author{
By Charles H. T. Townsend, Piura, Peru
}

The system described below was devised a year ago by the writer on his arrival in Peru. It is especially adapted for use in a region where little or no entomological work has previously been done, and where much time must elapse before determinations of species can be secured, but it is equally applicable to all general entomological work. It has been in use for a year, and has so far fulfilled every reasonable expectation.

Note slips of the standard card-catalog size are used, but any size desired can be substituted for these. Colored cards are used for heads. Plant names are the chief heads, but certain others are included as suit the needs of the work. A single species of plant may form a head, or a single genus; and likewise a single species of insect, or a group of insects. Insect heads are used only for certain groups or categories that do not fall naturally under plant heads, or for certain injurious species that are being exhaustively investigated and dealt with economically.

The heads are allotted numbers from 1 to 1,000 , usually two numbers being reserved for each. In exceptional cases four numbers are reserved for a head. Thus Hemichionaspis minor, which as a pest of cotton, is being specially investigated in Peru, is allotted numbers $1,2,3,4$, head to include not only that species but all allied species whose parasites promise well for use against it. Two numbers are given to Dysdercus. Six numbers are reserved for the cotton squareweevil and its allies, whose parasites may be used against it; since it has recently developed that this newly discovered cotton weevil is the cause of more damage to cotton in Peru than all other insects combined. Two more numbers are given to all other cotton insects. The great mass of heads are plant heads, but non-plant heads other than the above are human and animal disease-transmitters and parasites, wasps, bees, stored foods, silk, hides, drugs, collected microparasites and others not connected with hosts, coccinellids, ants, termites, locusts, household insects, jiggers, ticks, museum pests, etc. These are all the nonplant heads that have so far been needed, and these with the plant heads have brought the numbers in a year to the 800-mark.

When the first thousand numbers have been used for heads, the same numbers can be used over again with the letters of the alphabet prefixed; as $A 1$ to $A 1,000, B 1$ to $B 1,000$, etc. This allows of an indefinite number of heads. The heads and slips are arranged consecu- 
tively by numbers. The colored catch cards bear the head, and its initial numbers, as: $-247,-248$, citrus fruits.

Under each head numbers are multiplied as follows: $A$ head with numbers 247,248 , follows these numbers with $1,247,1,248,2,247$, $2,248,3,247,3,248$, etc. Thus a head with two numbers admits of two hundred species being placed under it before the numbers reach the six-figure space. In all cases the final numbers are the same for a head.

The system, as so far outlined, applies only to insects that are found on their respective food-plants, and to those falling under the nonplant hears adopted.

All enemies, whether parasites or predatory insects, of the species under the above heads, are designated by adding to the host-number the following:

${ }^{\circ} \mathrm{a}$ - Egg-parasites.

${ }^{\circ} 2 \mathrm{a}$ - Dipterous entoparasites of any stage.

${ }^{\circ} 3 \mathrm{a}$ - Hymenopterous entoparasites of any stage.

${ }^{\circ} 4 \mathrm{a}$ - Heteropterous predaitors of any stage.

${ }^{\circ} 5 \mathrm{a}$ - Coleopterous predators of ditto.

${ }^{\circ} 6 \mathrm{a}$ - Lepidopterous predators.

${ }^{\circ} 7 \mathrm{a}$ - Dipterous predators.

${ }^{\circ} 8 \mathrm{a}-$ Neuropterous predators.

${ }^{\circ} 9 \mathrm{a}$ - Hymenopterous predators.

${ }^{\circ} 10 \mathrm{a}$ - Acarid ectoparasites or predators.

Other enemy heads can be added for stylopid or other entoparasites, and for other predators or ectoparasites, etc. The letters of the English alphabet are to be used, and then doubled, tripled, etc., if required; as $247^{\circ} 3 a$ to $247^{\circ} 3 z, 247^{\circ} 3 a 2$ to $247^{\circ} 3 z 2,247^{\circ} 3 a 3$ to $247^{\circ} 3 z 3$, etc., variations as preferred may be adopted.

Hyperparasites, etc., can be numbered with a repetition of the above enemy suffixes added to the host-number; as $247^{\circ} 2 \mathrm{a}^{\circ} 3 \mathrm{a}$ to $247^{\circ} 2 \mathrm{a}^{\circ} 3 \mathrm{z}$, etc.

I have used the suffix ${ }^{\circ} 20$ (a to $z$, etc.) for fungous diseases; others can be added for bacterial diseases, etc.

. It will be seen that this system is highly elastic, and can be used at once before the names of any of the species of insects are known. Only the names of the plants are needed.

An index of the heads is kept separate, for the purpose of readily finding the numbers belonging to each.

With any other system the greatest confusion exists until the species of insects are known by name. With this system, order is maintained throughout, as well as a food plant catalog of the species. 
Under the present system, as soon as species are identified, the slips belonging to them may be arranged under generic heads in alphabetic order, thus transferring the same slips from the original plant and other head system of the first index to a second index system using the generic names of the insects. At the same time the names of the insects are entered under the original plant and other heads, and the first index is thus retained as a cross-reference catalog to the food-plants and habits.

It will be seen that when a species has two or more host plants or host insects it will receive as many numbers under the respective heads. Also species associated with one being specially investigated for purpose of bringing together at a glance the parasites available for the latter will take further numbers in consequence. This may be thought a serious objection, and on this account I at first had some misgiving as to the system, but it has not proved so in practise. It makes no difference finally how many numbers a species may have, since each number must necessarily refer at once to the species; on the other hand, it would cause great confusion if two or more species were to appear under the same number. Upon the identification of a species, all the slips, under whatever numbers, come together under its name in the second index, and at the same time the records are left for cross-reference in the first index. The first is a number index, relating to food-plants and habits; the second is a name index, relating to genera and species. The first index system, with names incorporated, will be found of immense practical advantage as a supplement to the second index system.

While this scheme has been devised to meet the wants of an isolated region where entomological work is being inaugurated practically for the first time, it will be quite readily applicable to general economic work at any stage of records. Such species of insects as have been determined will appear in the second index while all notes on species still unnamed may be renumbered and arranged, with new slips of those determined under the first system which is thus elaborated into a food-plant and food-habit index. Such renumbering should prefix some character to the above numbers, as $\mathrm{N}$ (meaning new number), or an asterisk or Greek letter, or the number may be written in red ink or otherwise distinguished until the old numbers have been exceeded. The new numbers can be added to the specimens without removing the former numbers. For the second system a generic index is found in the head cards alphabetically arranged. The beauty of the whole scheme is that it is capable of immediate application, without the necessity for the names of the insects being predetermined, and of systematic and unlimited extension on the same lines as begun, the 
records of any species being at once available at all times. I am able at a moment's notice to find any particular note that I have made during the past year on any one of the hundreds of species of insects studicd, whether yet determined or still without name, and anyone who familiarizes himself with the scheme as outlined can do the same. This is of course the test of any system of note keeping. Its proof is in its convenience and utility. I know of no other general record scheme that is at once so simple and so conveniently available at all stages of the work.

\section{SOME WAYS OF REACHING THE PUBLIC}

By H. A. Gossard

Last year I presented by title to the Association of Economic Entomologists a paper which has since been published in the Journar of Economic Entomology on "The Value and Makc-up of State and County Fair Exhibits." In this, I discussed one of the methods I use to acquaint the public with the entomological work of the Ohio Agricultural Experiment Station. This special feature of our work will, therefore, need no further mention in this paper. It is with the hope that a discussion of other methods of gaining publicity may bring to me some profitable suggestions from my fellow-workers and that I may impart a few to them that I offer this paper.

Of course, the main reliance of the official economic entomologist for publishing his results must be through the customary medium of publicity used by the institution with which he is connected. This is usually by means of the bulletin, circular and annual report. Professor Sanderson has given so good a discussion relating to "Publications of the Station Entomologist" in No. 4, Vol. 2 of the Journal of Economic Entomology that I shall pass over this subject quite briefly:

I wish, however, to emphasize the recommendation that such publications be generously illustrated. A carefully chosen, significant cut on the outside cover page of such a pamphlet secures for it a favorable impression before it is perused, and nearly always insures its being read. Abundant and good illustrations should also be scattered through the body of the pamphlet. The contents of the bulletin must, of course, depend upon the studies of the writer, but every entomologist has many lines of work open to him, and he should remember in making his selection that some of these will yield imme- diate and valuable results to his constitutents, while other questions equally easy to choose, and equally important, considered from the 